\title{
A CONTRIBUIÇÃO DO PENSAMENTO FREIRIANO NO PROCESSO DE EMPODERAMENTO DA JUVENTUde DA COMUNIDADE QUILOMBOLA DE Paratibe, JoÃo Pessoa - PB: uma análise DA EXPERIÊNCIA DO PROJETO SOCIAL PARATIBE EM AÇÃO
}

IANY ElIZABETH DA COSTA

Universidade Federal da Paraíba (UFPB), João Pessoa, Paraíba, Brasil

Resumo: O presente artigo busca analisar a contribuição do pensamento freiriano no processo de empoderamento da juventude da Comunidade Quilombola de Paratibe, João Pessoa - PB, a partir das práticas em Educação Popular no Projeto Social Paratibe em Ação. Buscamos demonstrar como a prática educativa fundamentada no pensamento freiriano contribui no processo de fortalecimento da identidade e da cultura da juventude quilombola. Para isso, destacamos a contribuição de Paulo Freire a partir da análise da experiência do Projeto Social Paratibe em Ação, utilizando revisão bibliográfica e entrevistas, a fim de compreender a importância do fortalecimento da identidade quilombola por meio de uma educação emancipadora.

Palavras-chave: Paulo Freire. Juventude quilombola. Empoderamento. Paratibe em Ação. 
INTRODUÇÃO

Neste artigo buscamos analisar a contribuição do pensamento freiriano no processo de empoderamento da juventude da Comunidade Quilombola de Paratibe, João Pessoa - PB, a partir das práticas em Educação Popular do Projeto Social Paratibe em Ação. Despertamos nosso interesse pela temática durante a pesquisa de campo nesta comunidade realizada entre os anos de 2014-2016, para a construção da dissertação de mestrado intitulada "A ressignificação da Identidade Quilombola na Comunidade de Paratibe, João Pessoa - PB: Análise a partir dos processos de resistência" PPGDH/UFPB. Nesse processo de coleta de dados, tivemos a oportunidade de manter contato direto com a experiência em Educação Popular do Projeto Social Paratibe em Ação, motivando, assim, o presente artigo.

A Educação Popular como campo de conhecimento, constituída pela defesa da Educação Humanizadora e Emancipadora, encontra nas obras de Paulo Freire: Pedagogia do Oprimido (1981) e Educação como Prática de Liberdade (2002), a síntese da problematização da Educação Bancária, que desumaniza o educando, nos, demonstrando outra forma de pensar o sujeito, a partir das vivências deste com o meio em que vive, partindo do princípio de que o povo produz saber, sendo necessário valorizá-lo dentro dos processos de ensino e aprendizagem. Freire problematiza a passividade da educação formal: tradicional, excludente, em prol, de uma educação emancipadora, fundamentada no diálogo e na formação crítica do sujeito como ser pensante.

A semente de germinação do Projeto Paratibe em Ação surgiu a partir de uma intervenção social realizada pela Escola de Capoeira Afro-Nagô, no Quilombo de Paratibe, João Pessoa - PB, no ano de 2006. Inicialmente esta escola de capoeira liderada pelo Mestre Zunga fazia um trabalho de afirmação da identidade negra, valorizando a cultura quilombola, por solicitação das lideranças dessa comunidade quilombola (GONÇALVES, 2011). Posteriormente, a ação na comunidade foi ampliando, culminando na fundação do referido projeto, no ano de 2009, sob a liderança no instrutor de capoeira J.P., que a partir da concepção freiriana promove uma Educação que valorize as raízes culturais, as músicas, os cabelos, enfim, toda a estética negra como símbolos da resistência cultural e simbólica na Diáspora Africana.

Desta forma, buscaremos perceber a contribuição do pensamento freiriano na experiência em Educação Popular realizada pelo Projeto Social Paratibe em Ação, na Comunidade Quilombola de Paratibe, destacando, principalmente, como a valorização da identidade quilombola e da estética negra contribui para o empoderamento da juventude deste quilombo. 
Explicitaremos nesse texto a importância do pensamento freiriano na construção da imagem positiva da história do povo negro e do povo quilombola, como um instrumento importante no processo de autoafirmação da juventude do quilombo de Paratibe, João Pessoa - PB.

\section{A contribuição do pensamento de Paulo Freire na Educação Não For- MAL: CONSTRUINDO CONHECIMENTOS PARA ALÉM DOS MUROS DA ESCOLA}

A Educação é um processo constante de construção do conhecimento do ser humano, fruto das vivências em sociedade, que não estão inseridas apenas nos contextos escolares, mas, que contribuem na relação ensinoaprendizagem dentro da sala de aula. Para Brandão (2004, p. 17) a Educação "abrange todos os processos de formação do individuo", que podem acontecer de diferentes modos, em diferentes espaços sociais, mais que tercem a experiência individual e coletiva do sujeito em sociedade, contribuindo para a sua autoafirmação enquanto sujeito, consciente de seu papel social e crítico da negação dos direitos socializantes.

A Educação não se constitui apenas como um processo de aprendizado que se desenvolve ao longo da vida, mas também, é um direito, um dever do Estado, conforme está disposto na Declaração Universal dos Direitos Humanos (ONU, 1948, p. 5):

No sentido do pleno desenvolvimento da personalidade humana e do fortalecimento do respeito pelos direitos humanos e pelas liberdades fundamentais. A instrução promoverá a compreensão, a tolerância e a amizade entre todas as nações e grupos raciais ou religiosos, e coadjuvará as atividades das Nações Unidas em prol da manutenção da paz.

Nesse aspecto, a Educação é um direito fundamental, por isso, é importante fortalecer as abordagens educativas que respeitem a diversidade étnico-racial, cultural, religiosa, política e de gênero, devendo ser valorizadas como componente educativo porque é fruto dos saberes de mundo dos(as) educandos(as). Pois, não se trata apenas de oferecer instrução, mas sim, de dar garantias que todo o ser humano tenha"o direito de participar livremente da vida cultural da comunidade, de usufruir das artes, de participar do processo científico e de seus benefícios" (ONU, 1948, p. 5), garantindo que estes(as) educandos(as) possam se enxergar de forma positiva nos conteúdos educacionais dentro da escola.

É garantir que o conjunto de saberes provenientes das vivências individuais e coletivas dos sujeitos em sociedade, faça parte da formação do saber escolar, é compreender que é possível aprender com a cidade, com os 
grupos familiares, com as músicas populares, com as danças, com as comidas típicas, enfim, com os modos de ser e viver em sociedade, tanto quanto, se aprende nas salas de aula.

Desta forma, defende uma educação que vai além do conteúdo preestabelecido, é buscar um modo de educar que entenda a leitura de mundo dos educandos e educandas (FREIRE, 1981). Composta por uma série de representações culturais e simbólicas que fortalecem o sentimento de pertencimento e de memória afetiva destes sujeitos. Sendo assim, esses saberes visam desconstruir a perspectiva da Educação Formal que atribui à escola como única fonte de saber e ao docente como único mediador deste saber. Negando que o discente começa a aprender, a partir, do momento que ele se entende no mundo, como exemplifica bem Freire (1981, p. 15) quando expõe que:"fui alfabetizado no chão do quintal da minha casa, à sombra das mangueiras, com palavras do meu mundo e não do mundo maior dos meus pais. O chão foi o meu primeiro quadro-negro; gravetos, o meu giz".

Defender a educação formulada, a partir, da vivência de mundo dos(as) educandos(as), é lutar pela efetivação da Educação Popular como um modo de ver, sentir e agir diferentes dentro e fora da sala de aula tradicional, é abrir espaço para que os alunos e alunas tornem-se sujeitos participativos do processo educativo, saindo, da perspectiva da "educação bancária", vista por Freire em seu livro Pedagogia do Oprimido (1981) como um modo de ensinar tradicional, pautado, na exclusão do saber popular ou não formal, bem como, pela predominância do silenciamento dos alunos e alunas no ato de ensinar/aprender.

Paulo Freire convida os educadores à reflexão do processo de aprendizagem, saindo do campo da formalidade, do conhecimento preestabelecido, da moldura social, para provocar no(a) educador(a) uma posição diferente, um novo olhar sobre as vivências de mundo dos alunos e alunas, como experiências educativas que necessitam compor o chão da escola. Defende que o ato de educar/aprender esteja fundamentado no princípio da humanização do processo educativo, na visibilidade dos indivíduos, como sujeitos sociais pensantes, que necessitam assumir uma postura crítica frente aos processos de exclusão cotidianos, sendo fundamental, a efetivação de uma Educação que os convide a problematizar o lugar social em que se encontram.

Por isso, Freire (1981) nos coloca a importância da formulação de uma metodologia pedagógica participativa que visa à libertação do homem, por intermédio da Educação, não uma educação construída apenas com os livros, mas sim, uma educação fundamentada na vivência do homem em sociedade, nos seus modos de fazer e de agir. No reconhecimento da opressão cotidiana 
a que estão submetidos homens, mulheres e crianças das chamadas "classes populares"(VALLA, 2009), que conforme Freire (1981) passa a compreender o valor dos seus saberes de mundo a partir de uma educação problematizadora, que visa despertar no educando(a) a conscientização, a capacidade de reivindicar, de lutar contra a opressão/opressor, pois, é por meio do despertar da consciência crítica que o indivíduo passa a compreender que a sua vivência social, produz cultura, tem valor equivalente ao saber escolar tradicional.

Freire (1981) defende que a educação precisa está fundamentada no diálogo, na ação e na reflexão, como mecanismos que emancipam as práticas educativas, porque, compreendem que o(a) educando(a) também é educador(a) e que o(a) educador(a) também e educando(a), ou seja, aprender a aprender é perceber que os saberes não formais e os saberes formais, são frutos das vivências sociais e precisam dialogar no intuito de fortalecer no(a) educando/educador(a) a valorização, a autoafirmação, baseada na perspectiva do ser mais.

A Educação Popular fundamentada na perspectiva freiriana, evidencia-se como uma proposta metodológica que dialoga diretamente com a concepção de saber não formal, pois, ela é fruto das vivências coletivas dos movimentos sociais. Sendo uma abordagem metodológica voltada para o fortalecimento do(a) educando/educador(a) como um sujeito social, critico e consciente, capaz de problematizar sua realidade, de reivindicar seus direitos, porque, passa a compreender que é capaz de transformar o meio social em que vive, é capaz de conquistar e produzir cultura, combatendo qualquer atitude arbitrária que vise diminuir sua condição de cidadão de direitos.

Esse processo de empoderamento ${ }^{1}$ do(a) educando/educador(a) só se constitui por meio de uma práxis educativa que crie mecanismos para a mudança dos processos educacionais, por meio de uma abordagem problematizadora, que conforme o pensamento freiriano busca ir "para além das formulações proposicionais para a educação, ao demarcar o fenômeno de 'poderamento' cultural das pessoas como fenômeno de libertação humana" (MELO NETO, 2015, p. 139-140). Essa libertação humana vem do processo de humanização e indignação frente às injustiças sociais, que emancipa o sujeito, a partir, de uma educação que problematiza os conflitos sociais.

O empoderamento é entendido como"um processo de fortalecimento e autonomização de sujeitos e grupos nas suas relações e práticas cotidianas, em especial aqueles que passam por situações opressoras e discriminatórias" (ARRAES et al., 2012, p. 74). Que revela os "potenciais de uma pessoa, através da reflexão coletiva e diálogo contínuo, onde as diferenças cedem espaço para propósitos e objetivos comuns - consequentemente transformando vidas" (CAVALCANTE JR., 2005, p. 51), nesse sentido, empoderar é incentivar por 
meio da educação que o(a) educando(a) gradativamente tome consciência e autonomia participativa, para problematizar a violência, a discriminação e a desigualdade em todos os ambientes sociais em que convivem dentro e fora do espaço escolar.

Freire (2002) em seu livro Educação como prática de liberdade encontramos mecanismos para compreender que o empoderamento só encontra êxito enquanto metodologia popular participante a partir do momento em que o(a) educando/educador(a) ultrapassa a concepção de viver, pois, compreender que viver vai além do simples fato de está no mundo, o viver se completa com a compreensão do existir, mas, não uma existência individual, e, sim, uma existência coletiva, fortalecida na percepção das problemáticas em grupo, visando à problematização e a superação delas.

Para Freire (2002) o ato de educar tem que está associado à percepção de que o(a) educando/educador(a) possui um conjunto de práticas sociais que compõe as teias de saberes que o constitui como sujeito em sociedade. Ele nos convida a entender que educar é um ato de amor, de coragem e de resistência, porque convida ao educador a sair da sua zona de conforto, a problematizar sua formação, sua forma de ensinar. No intuito, de instigar a mudança na formação dos conteúdos programáticos, que introduzam conhecimentos populares, como ferramentas educativas que valorizem o sujeito e fortaleçam a luta por igualdade e justiça social.

$\mathrm{O}(\mathrm{A})$ educando/educador(a) quando percebe que o seu saber é valioso, reafirmar dentro dele o sentimento de pertencimento a sua cultura local, e o seu modo de ser e de viver torna-se crítico, abandonando a aparente passividade, imposta pelo modelo formal de aprendizado. Para adquirir uma consciência crítica, capaz de interpretar os processos de negação de direitos, questionando e buscando formas de combatê-las e superá-las por meio da organização popular.

O pensamento freiriano contribui na compreensão da importância da valorização do saber de comunidade, nos convidando a abandonar a passividade em busca de conhecer as metodologias populares que trazem consigo a história da resistência das classes ditas "populares" no processo de formação do Brasil. Buscando rememorar as experiências populares, visando compor o processo educativo que vem de fora da escola para emancipar-se dentro dela. Ou seja, valorizar a educação não formal é compreender que ela é parte do processo de humanização do indivíduo, fruto de diversas experiências que começam fora do âmbito escola e devem ser visibilizadas e reconhecidas pelo saber escolar, fortalecendo no(o) educando/educador(a) a capacidade de questionar o seu lugar social, a partir, da tomada de consciência 
dos seus direitos, como apresentaremos a seguir na análise das vivências do Projeto Social Paratibe em Ação.

Empoderando a juventude da Comunidade Quilombola de Paratibe, João Pessoa - PB: Uma anÁlise da experiênCIA do Projeto Social Paratibe em AÇÃO

Para compreendermos o processo de empoderamento da juventude do quilombo de Paratibe, João Pessoa-PB, a partir da contribuição do pensamento freiriano presente nas práticas em Educação Popular do Projeto Social Paratibe em Ação. Nós precisamos primeiro, situar o campo de estudo da nossa análise, sendo assim, a primeira determinação oficial sobre o termo quilombo, é oriunda do Brasil Colônia, estabelecida nas cartas do Conselho Ultramarino Português (1740) que definiu quilombos como sendo toda habitação de negros fugidos que passem de cinco, em parte desprovida, ainda que não tenham ranchos levantados nem achem pilões neles (CUM, 1740).

A categoria de quilombo/quilombolas ${ }^{2}$ conhecida na atualidade, foi instituída a partir do art. 68 do Ato das Disposições Transitórias da Constituição Brasileira de 1988 (BRASIL, 1988), inaugurando assim "um novo movimento identitário dentro do movimento negro, passando os quilombolas a exigirem e articularem sua própria luta por demandas sociais específicas" (COSTA, 2016, p. 31).

A Comunidade Quilombola de Paratibe, iniciou sua ocupação territorial na região de Paratibe há pelo menos 300 anos, conforme dados encontrados no Relatório Técnico de Identificação e Demarcação - RTID da referida comunidade (GONÇALVES, 2011). No qual, existem registros documentais, que nos dão conta da presença deste referido quilombo, no final do século XVIII. Tavares (1989) nos expõe que existem apontamentos que confirmam a presença desta comunidade na mesma localidade, no século XVIII:

Em fins do século XVIII, segundo a documentação, existiam dois quilombos na Mata Sul da Paraíba, o quilombo de Paratybe, cujos moradores, segundo Archimedes Cavalcante, atacavam os viajantes e pequenos comerciantes que faziam o trajeto Cidade da Paraíba-Recife e o quilombo do Guajú, o primeiro deles ainda no termo da capital e o segundo e menos conhecido em terras da Vila do Conde (TAVARES, 1989, p. 157).

A população do antigo Quilombo de Paratibe ocupou o território que formava a Sesmaria pertencente à Ordem Religiosa dos Carmelitas, mantendo certa autonomia dentro dos termos da capital. Desta forma, durante todo o 
século XVIII e até a primeira metade do século XIX, os quilombolas de Paratibe, ocuparam esse território sem o registro de posse da terra (GONÇALVES, 2011), apenas passando a escriturá-la no ano de 1850, no advento da Lei de Terras (SILVA, 2015), conforme destaca Tavares (1989, p. 158):

Muitos posseiros, entre eles o mulato João José Pereira de Carvalho, que registrou duas propriedades, uma em seu nome e da esposa Marcelina Ramos de Oliveira, denominada Mussumagro e a outra propriedade, denominada Paratybe, em nome de uma mulher chamada Maria Rosa da Conceição Carvalho.

Essas duas propriedades, habitadas, quase exclusivamente por negros, originaram os atuais bairros, que possuem a mesma denominação; os moradores mais antigos dessas comunidades, provavelmente são descendentes dos primeiros quilombolas, pois nem a documentação, nem a historiografia, descrevem uma expedição punitiva para destruir o referido quilombo, [...] Sendo assim, ao menos alguns quilombolas, embora as fontes não esclareçam como, foram não só importantes agentes produtores do espaço, como também se tornaram proprietários do disputado solo da Mata Sul da Paraíba.

A atual Comunidade Quilombola de Paratibe é formada por um grupo de aproximadamente 300 pessoas remanescentes dos primeiros aquilombados, encontram-se hoje em processo de titulação do território ancestral, iniciado no ano de 2006 (GONÇALVES, 2011; COSTA, 2016). Nossa aproximação com a comunidade nos direcionou a experiência educativa do Projeto Social Paratibe em Ação, tendo em vista que nosso objetivo no processo dissertativo era compreender como a questão identitária foi se (re)construindo nesta comunidade, e o referido projeto nos qual tivemos contato no campo, nos deva importantes indícios sobre a prática da pedagogia freiriana. Esse projeto tem como finalidade despertar a identidade positiva da juventude negra por meio de um conjunto de ações sistemáticas que envolvem dança, alfabetização e estética negra, a fim de fortalecer a juventude quilombola.

As raízes do Projeto Paratibe em Ação conforme explica Gonçalves (2011), foi semeada a partir do convite realizado por uma das lideranças do quilombo de Paratibe, ao Mestre Zunga da Escola de Capoeira Afro-Nagô no ano de 2006. Inicialmente, as aulas de capoeira na comunidade tinham o objetivo de afirmação da identidade negra, valorizando a cultura quilombola, através da capoeira, do maculelê e do resgate da história de luta do quilombo dos Palmares e do seu líder Zumbi (GONÇALVES, 2011).

Posteriormente, a atuação da Escola de Capoeira foi ampliada, culminando na criação do referido projeto, no ano de 2009, sob a liderança no instrutor de capoeira J.P., que buscou integrar as práticas de educação libertária 
encontradas em Paulo Freire em consonância com a valorização da estética negra, visando construir junto com a juventude quilombola, um processo educativo fundamentado na valorização das raízes culturais, das músicas, dos cabelos, enfim, toda a estética negra como forma de resistência cultural e simbólica. As ações do Projeto Paratibe em Ação iniciaram-se da seguinte maneira, conforme expõe J.P., em entrevista concedida durante nossa pesquisa:

Quando começamos a fazer o trabalho de capoeira na Comunidade Quilombola de Paratibe, nós fomos observando que eles tinham uma dificuldade grande de se aceitar como negros. Era muito difícil para nós, falarmos sobre a cultura africana na capoeira, por que fazemos sempre essa ponte quando vamos formar um grupo de capoeira. Primeiro nós resgatamos a história de luta do povo quilombola, dando destaque a luta dos quilombolas de Paratibe e a figura do Zumbi, para depôs iniciamos a prática da capoeira e do maculêlê (J. P., 2015, JOÃO PESSOA-PB).

Y.A., uma das lideranças jovens do Quilombo de Paratibe, contou-nos como foi o processo da sua inserção da escola de capoeira da Afro-Nagô, segundo ela:

No início eu mesmo tinha muita dificuldade de compreender que ser negro e ser quilombola são coisas muito boas, eu cresci com as pessoas das localidades vizinhas tendo preconceito com a gente, dizendo que somos índios, colocando uma ideia ruim de assumir nossa história, de assumir como somos. Ai, a partir, do Paratibe em Ação, a gente foi tendo uma ideia diferente, primeiro, porque o Pitoco e outros professores que passaram por aqui começaram a falar da história do povo negro no Brasil, a falar do valor que a gente tem, lembro que fizeram até uma oficina de turbante e trança afro, foi daí que eu comecei a me valorizar mais, a dar mais valor a minha história (Y.A., 2015, JOÃO PESSOA - PB).

Segundo Gonçalves (2011) as primeiras ações da Escola de Capoeira Afro-Nagô eram realizadas pelo Mestre Zunga, que dava as aulas para as crianças e os jovens da comunidade, depois, a continuidade do trabalho ficou a cargo de dois capoeiristas de seu grupo, conhecidos como Lampião e Pitoco, que passaram a atuar de forma voluntária. Conforme entrevista J.P. relatou-nos como o trabalho social foi se intensificando a partir do:

Entrosamento entre a gente e a comunidade, nós fomos vendo uma série de carências que eles tinham, tanto na questão da autoafirmação, quanto no rendimento escolar, pois, constatamos que muitos deles, não sabiam nem ler bem escrever, tendo dificuldades de assinar a lista de presença das atividades. Foi a partir, dessa percepção que começamos um reforço escolar por conta própria (J.P., 2015, JOÃO PESSOA - PB). 
A partir dessa constatação, como mencionado na fala acima descrita, foi iniciado um processo de mobilização social para reverter o quadro de baixo rendimento escolar e evasão. Para isso, a primeira ação foi a criação de um reforço escolar na comunidade, conforme destaca Gonçalves (2011, p. 50), ele "conseguiu 25 carteiras com o setor do patrimônio da Universidade (UFPB) e deu início a uma turma", com o objetivo de alfabetizar e ajudar nas atividades escolares das crianças e jovens participantes do grupo de capoeira, esse reforço escolar funcionou inicialmente nos fundos da casa de D. Silvinha, mãe da presidente da Associação quilombola J.P.R. (GONÇALVES, 2011), como vemos na imagem destacada abaixo:

Figura 1- Criança Quilombola no Reforço Escolar do Projeto Social Paratibe em Ação

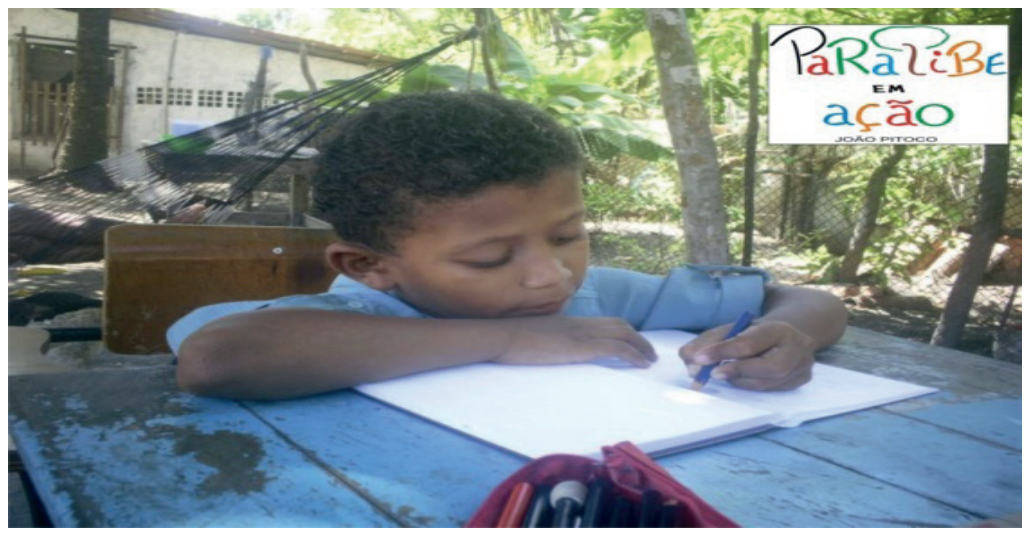

Fonte: Acervo Pessoal Paratibe em Ação (2009). Disponível em: <http://paratibe-em-acao. blogspot.com.br/>. Acesso em: 20 jul. 2015.

As aulas desse reforço eram ministradas pelo instrutor de capoeira J.P., de forma voluntária durante os anos de 2007 a 2009, até que ele foi:

Contratado pela Prefeitura de João Pessoa em 2010, para continuar com o reforço em Paratibe. O Contrato dele foi conseguido por meio de uma articulação entre a Associação Negra de Paratibe e a AACADE Junto a Prefeitura (GONÇALVES, 2011, p. 50).

Passando a incluir também outras atividades como jiu-jitsu, judô, recreação e aulas de violão, todas elas realizadas por voluntários, com o apoio financeiro de colaboradores (J.P., 2015, JOÃO PESSOA-PB).

Visando ampliar a leitura de mundo da juventude quilombola de Paratibe, foram realizados diversos passeios e outros espaços de cultura da 
cidade, como idas ao Teatro, ao Cinema, aos pontos turísticos da cidade de João Pessoa-PB, bem como, passeios dentro da própria comunidade, como visitas ao rio do Padre, à mata da Portela, ao Mangue, com o objetivo de conhecer sua história e valorizar sua preservação. Destacamos abaixo fotos das ações empreendidas pelo projeto:

Figura 2 - Visita ao Teatro Ednaldo do Egyto

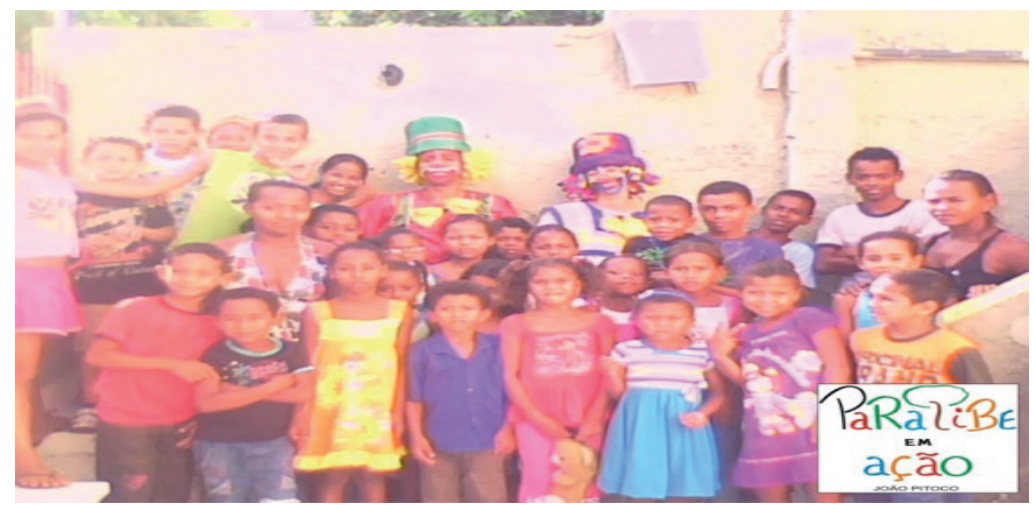

Fonte: Acervo Pessoal Paratibe em Ação (2009). Disponível em: <http://paratibe-em-acao. blogspot.com.br/>. Acesso em: 20 jul. 2015.

Figura 3 - Foto no fim do treino semanal de jiu-jitsu

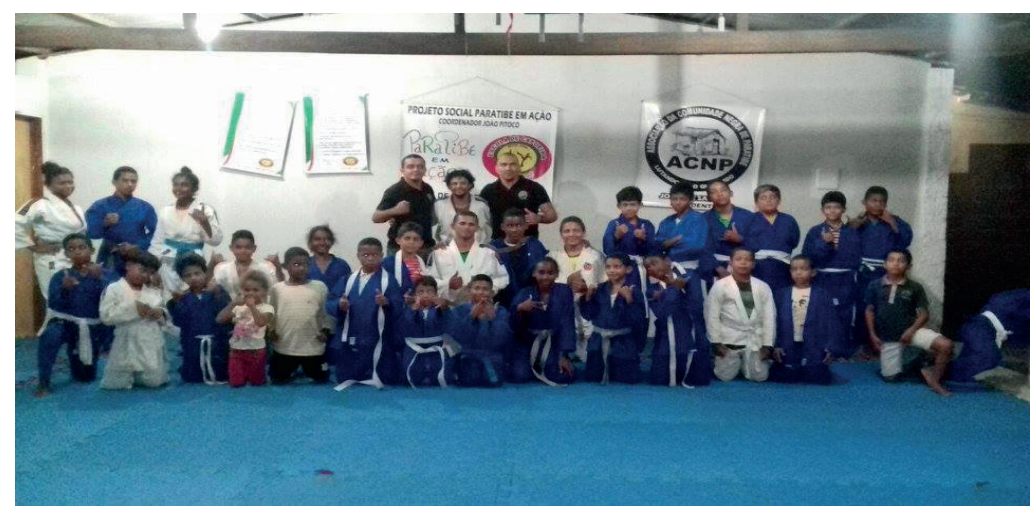

Fonte: Acervo Pessoal Paratibe em Ação (2016). Disponível em: $<$ http://paratibe-em-acao. blogspot.com.br/>. Acesso em: 20 jul. 2016. 
Figura 4 - Apresentação Cultural do Projeto Paratibe em Ação, na Culminância Bimestral do Projeto Educação Quilombola na EMEF Antônia do Socorro Silva Machado

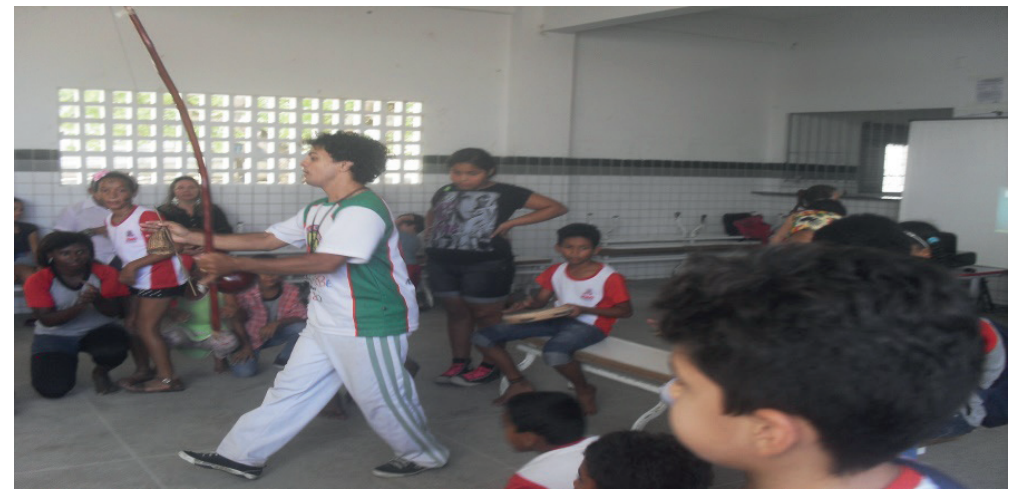

Fonte: Acervo Pessoal I.E.C. (2016).

Atualmente, estão envolvidos no referido projeto, cerca de 50 crianças e jovens do Quilombo de Paratibe, que participam também de ações de preservação das áreas verdes da comunidade, bem como, se reúnem todos os sábados dentro da comunidade, em um pequeno galpão e fora dela no ginásio da EMEF Antônia do Socorro Silva Machado (CAVALCANTE, 2013), que está historicamente relacionada com a comunidade desde a sua fundação (COSTA, 2016), conforme destacamos em foto abaixo:

Figura 5 - Foto do treino semanal da Capoeira

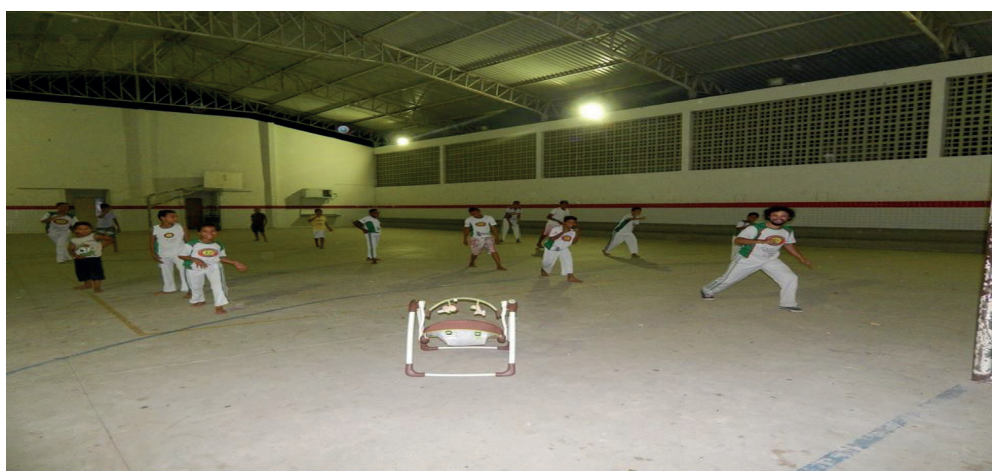

Fonte: Acervo Pessoal Paratibe em Ação (2016). Disponível em: < http://paratibe-em-acao. blogspot.com.br/>. Acesso em: 20 set. 2016. 
As atividades realizadas pelo Projeto Social Paratibe em Ação, buscam fortalecer a identidade da juventude quilombola, por meio da valorização do lugar, do território, da cultura ancestral. J.P. questionado em entrevista sobre o motivo do sucesso do projeto social, expõe que:

Eu acredito que o sucesso do Projeto Social Paratibe em Ação é devido ao empenho da própria comunidade quilombola que desde o início das nossas atuações, sempre buscaram contribuir de alguma forma, seja com alimentos e água para nosso lanche coletivo após os treinos de capoeira, seja acreditando no nosso trabalho e incentivando a juventude a participar (J.P., 2015, JOÃO PESSOA - PB).

Essa participação da comunidade quilombola como destacou o coordenador do projeto, foi muito importante para o maior envolvimento da juventude, sendo um momento coletivo de construção do modo de ensinar e os modos de aprender, essa valorização vemos destacada na foto abaixo, com a apresentação das meninas do Projeto Social Paratibe em Ação, na festa do dia da Criança 2016 na Comunidade Quilombola de Paratibe:

Figura 6 - Apresentação da dança do Coco de Roda, Maculêlê e Ciranda das meninas do Projeto Social Paratibe em Ação

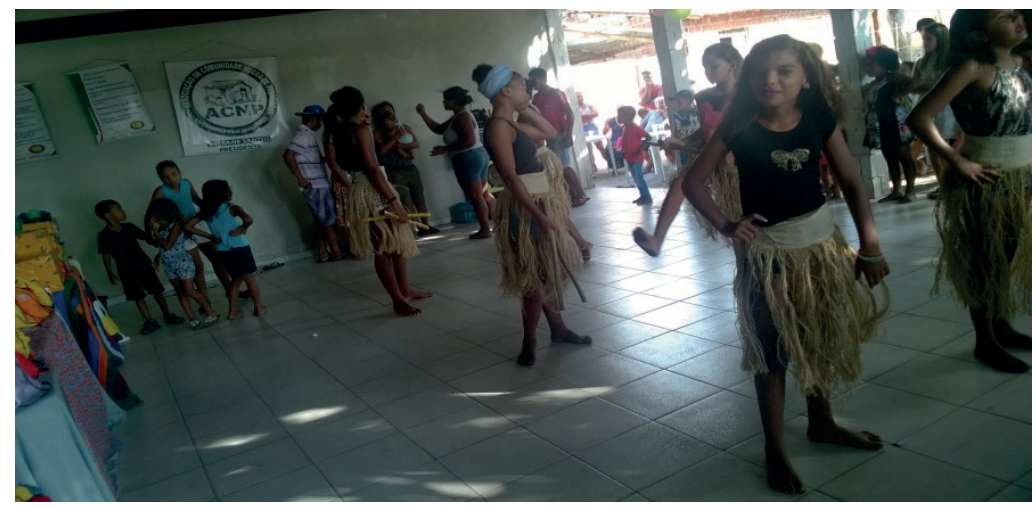

Fonte: Acervo Pessoal I.E.C (2016).

J.P. destacou ainda em sua entrevista que o modo de ensinar para mobilizar a juventude foi construindo, a partir, de uma metodologia popular, por meio de vários passeios com a juventude, dentro do território da comunidade, no qual ele foi descobrindo lugares tradicionalmente ocupados pela comunidade, tornando-se um educador/educando, que 
aprende com os educandos/educadores, dentro do território ancestral (J.P. 2015, JOÃO PESSOA - PB). Nesse processo, ele foi buscando elementos que sensibilizassem e despertassem o interesse da juventude em participar do projeto, principalmente, porque nas andanças na comunidade, ele começou a perceber a falta de perspectiva de crescimento entre os jovens, como consta no relato concedido a nós por meio de entrevista, descrito abaixo:

Eu tinha muita preocupação com a juventude aqui do quilombo, lembro bem que perguntei a uma menina assim:"Olha o que você vai ser quando crescer?" ela me respondeu "qualquer coisa". Não tinha perspectiva de melhoria de vida "qualquer emprego com um salário estava bom". Atualmente, podemos perceber que eles estão aprendendo a se organizar, a lutar pelos seus direitos e a pensar no futuro. Mesmo assim, a questão educacional aqui na comunidade ainda é um déficit muito grande porque muitos abandonam os estudos, são poucos aqui que estão em uma universidade. A falta de incentivo do Estado é um grande problema ainda aqui (J.P. 2015, JOÃO PESSOA - PB).

Essa preocupação com o futuro da juventude da comunidade, em consonância com a necessidade de mudança social destacada nas falas do coordenador J.P., possibilita-nos compreender que quando o diálogo educativo estabelecido entre a juventude quilombola e o Projeto Social Paratibe em Ação, fundamenta-se na pedagogia freiriana. Pois, a desconstrução do papel do educador como único mediador do saber e a experiência de conhecer a comunidade em seus espaços de ocupação colaboram para a formulação de uma pedagogia libertadora e emancipatória que visa incentivar a juventude a valorização positiva do "eu", como sujeito de direitos, participando ativamente do processo educativo, buscando novas formas de expressão e visibilidade.

O empoderamento da juventude quilombola de Paratibe tem se vinculado principalmente na conscientização do valor que a comunidade quilombola possui, por meio, do resgate das antigas cantigas do coco de roda, que são adaptadas aos novos sons do Reggae, Soul, Funk, Pop e o Dance, produzindo uma musicalidade que une o tradicional e o moderno. Conforme entrevista concedida por Y.A., uma das lideranças jovens, "antes nós tínhamos vergonha de ser negro, de aceitar nossos cabelos, nossa história, mas, com a integração ao projeto passamos a valorizar mais quem somos, nossas raízes" (Y.A. 2015, JOÃO PESSOA - PB).

A construção de um diálogo que valoriza a cultura e a história da comunidade tem ajudado a construir o processo de autodeterminação do povo quilombola de Paratibe, pois, o trabalho com a estética afirmativa de valorização do povo negro, fortalece o processo identitário, bem como, ajuda 
na articulação e conscientização da juventude sobre o seu papel na sociedade e a permanência do seu grupo étnico.

Sendo assim, a partir do trabalho do Projeto Social Paratibe em Ação, observamos a construção de uma pedagogia libertadora, incentivada por meio do resgate das tradições afro-brasileiras e da visibilidade positiva da estética negra, essas ações dialogam com a pedagogia freiriana porque reconhece a importância da leitura de mundo dos(as) educandos(as), utilizando-a como ponto de partida para a construção de uma educação emancipadora, que visa empoderar o sujeito, a partir do seu lugar social, formando indivíduos que lutam por seus direitos e repudiam preconceitos e atitudes arbitrárias, é o diálogo segundo Brandão (2004, p. 103) que fortalece as "relações de todas as coisas do mundo".

O empoderamento do sujeito a partir do conhecimento da sua história e dos seus direitos sociais, por meio, das ações deste projeto, tem buscando, conforme aponta J.P.:

Mostrar para as crianças e jovens da comunidade de Paratibe, como é importante valorizar a sua cultura local, a sua história. Que a primeira ação para começarmos a gostar de si mesmos, é se aceitar como somos. Por isso, nossas primeiras ações foram nossas no sentido de valorizar a própria fisionomia do grupo quilombola, mostrando que ter cabelo crespo é bom, é uma das características identitárias do povo negro (J.P., 2015, JOÃO PESSOA-PB).

Conscientizar-se de quem somos, de onde vimos, é redescobrir a nossa própria história de vida, nesse sentido a conscientização do nosso lugar no mundo é defendida por Freire (1981, p. 25), porque desperta: "a consciência de si". Assim, o processo de conscientização leva a lutar pela autoafirmação, ao afirmar-se enquanto cidadão, enquanto sujeito de direitos, que valoriza a sua história, fortalecido pelo processo de transformação social já não se deixa mais submeter, sabe seus direitos. Esta libertação segundo Freire (1981), é autentica, porque humaniza o sujeito, contribuindo para sua formação crítica e social.

As ações desenvolvidas pelo Projeto Social Paratibe em Ação, apresentadas ao longo do texto, nos oferece um importante exemplo de prática educativa emancipadora, fundamentada em Freire, na qual o diálogo entre educando/educador(a) e educador/educando(a), possibilitou a construção coletiva de uma práxis, que busca incentivar o empoderamento da juventude do quilombo de Paratibe, a começar pela valorização de sua história. Mostrando que é a reflexão crítica que fortalece o processo de libertação do indivíduo em sociedade, buscando a superação da desigualdade social, do racismo e dos processos de negação dos Direitos Humanos para comunidades tradicionais quilombolas. 


\section{CONSIDERAÇÕES}

Ao longo do texto destacamos as informações obtidas durante a coleta de dados na Comunidade Quilombola de Paratibe, João Pessoa - PB (2014-2016), destacando a experiência em Educação Popular do Projeto Social Paratibe em Ação, que concentra suas atividades pedagógicas fundamentadas na perspectiva freiriana, mantendo um diálogo aberto com a juventude quilombola, a fim de construir metodologias educativas coletivas, na qual, o educando é educador e o educador é educando.

O diálogo entre a Educação Popular em Freire e a Educação não formal do Projeto Social Paratibe em Ação, nos permitiu compreender a importância de se valorizar o saber comunitário proveniente da Comunidade Quilombola de Paratibe para a construção de uma metodologia participativa onde os educandos/educadores possam ter uma visão positiva do ser negro, ser quilombola, fundamentada no conhecimento do território ancestral quilombola e na percepção que a leitura de mundo do educando, fortalece a construção do saber.

O processo de valorização da história do povo negro e da estética da juventude quilombola de Paratibe, por meio de atividades culturais, lúdicas e simbólicas executadas pelo referido projeto, visam construir uma metodologia emancipadora e dialógica, a fim de formar sujeitos emponderados que desenvolveram a consciência crítica das desigualdades, e acima de tudo, fortaleceram em si mesmo a percepção da importância de sua história, a partir do posicionamento crítico "enquanto cidadãos do mundo, no mundo" (GOHN, 2006, p. 29). Esse empoderamento por meio do resgate da cultura negra e quilombola dialoga com a pedagogia freiriana, porque convida educandos e educadores a ampliarem sua visão de mundo, passando a valorizar o conhecimento e a história do povo quilombola por meio do trabalho com a valorização enquanto seres humanos e do lugar social que ocupam historicamente. 
THE CONTRIBUTION OF PAULO FREIRE'S IDEAS INTHE PROCESS OF EMPOWERMENT OF THE YOUTH FROM QUILOMBO OF PARATIBE, JOÃO PESSOA - PB: AN ANALYSIS OF THE EXPERIENCE FROM THE SOCIAL PROJECT PARATIBE EM AÇÃO

ABSTRACT: This article analyses the contribution of Paulo Freire's ideas to the process of empowerment of the youth from the Quilombola community of Paratibe, João Pessoa - PB, based on some practices in Popular Education in the social project Paratibe em Ação. We seek to demonstrate how the educational practice founded on Freire's ideas contributes to the process of reinforcement of identity and culture of the quilombola youth. In order to accomplish this intent, we highlight Freire's contribution from the analysis of the experience from the social project Paratibe em Ação based on literature review and interviews, so we can understand the importance of the quilombola empowerment through an emancipating education.

KEYwords: Paulo Freire. Quilombola youth. Empowerment. Paratibe em Ação.

LA CONTRIBUCIÓN DE LAS IDEAS DE PAULO FREIRE EN EL PROCESO DE EMPODERAMIENTO DE LA JUVENTUD DEL QUILOMBO DE PARATIBE , JOÃO PESSOA - PB: UN ANÁLISE DE LA EXPERIENCIA DEL PROYECTO SOCIAL PARATIBE EM AÇÃO

RESUMEN: Este artículo busca analizar la contribución del pensamiento de Paulo Freire en el proceso de empoderamiento de la juventud de la comunidad quilombola de Paratibe, João Pessoa - PB, a partir de las prácticas en Educación Popular en el proyecto social Paratibe em Ação. Buscamos demonstrar como la práctica educativa fundamentada en el pensamiento de Freire contribuye al proceso de fortalecimiento de la identidad y la cultura de la juventud quilombola. Para ello, destacamos la contribución de Freire a partir del análisis de la experiencia del proyecto social Paratibe em Ação, utilizando revisión bibliográfica y entrevistas para comprender la importancia del fortalecimiento de la identidad quilombola por medio de una educación emancipadora.

Palabras clave: Paulo Freire. Juventud quilombola. Empoderamient. Paraíba em Ação.

NOTAS

1 Neologismo derivado da tradução do inglês empowerment ("autorização"), empower ("autorizar", "dar poderes ou procuração", figurativamente "capacitar", "permitir", "habitar") (FORMIGA; ANDRADE, 2015, p. 167).

2 Autores como Almeida (1996) e O'Dwyer (2002) criticam esse conceito, pois, compreendem que "classificar" uma comunidade negra como quilombolas ou não quilombolas, perpassa pelo enquadramento de critérios definidos por leis, que longe de 
ampliar o acesso dessas comunidades às políticas públicas, acabam por negligenciar o passado de resistência do povo negro e abrir precedentes para a desqualificação das vivências dessas comunidades, pois, a obrigam a se enquadrarem no discurso do Estado, que os definem-no na forma da lei.

\section{REFERÊNCIAS}

ALMEIDA, A. W. B. de. Quilombos: sematologia face a novas identidades. In:

Frechal. Terra de Preto. Quilombo reconhecido como Reserva Extrativista. São Luís: SMDH-PVN, 1996. p.11-19.

ARRAES, A. K. M. et al. Empoderamento e controle social: uma análise da participação de usuários na IV Conferência Nacional de Saúde Mental Intersetorial em Natal (RN). Rev. psicol. polít, São Paulo, v. 12, n. 23, p. 71-85, jan. 2012.

BRANDÃO, C. F. Estrutura e funcionamento do Ensino. São Paulo: Avercamp, 2004.

BRASIL, Constituição da República Federativa do Brasil, 05 de Outubro de 1988. Disponível em: <http://www.planalto.gov.br/ccivil 03/constituicao/constituicao.htm>. Acesso em: 03 abr. 2017.

CAVALCANTE, Y. Y. L. O Ensino de Geografia na Educação Quilombola: experiência na Escola Municipal de Ensino Fundamental Professora Antônia Socorro da Silva Machado - Comunidade Negra Paratibe - PB. 2013. 199f. Dissertação (Mestrado em Geografia) - Universidade Federal da Paraíba, João Pessoa, 2013.

CAVALCANTE JR., F. S. Ler e escrever podem custar um mundo: uma década de investimentos para superação da pobreza de letramentos. Revista Mal-Estar e Subjetividade, Fortaleza, v. 5, n. 1, p. , mar 2005.

COSTA, I. E. A ressignificação da Identidade Quilombola na Comunidade de Paratibe: uma análise a partir dos processos de resistência. 2016. 176f. Dissertação (Mestrado em Direitos Humanos, Cidadania e Políticas Públicas) - Universidade Federal da Paraíba, João Pessoa, 2016.

FORMIGA, R. M.; ANDRADE, F. C. B. Empoderamento discente frente à violência na escola pela Educação em Direitos Humanos no programa "Mais Educação". In: MOREIRA, O. L. et. al. Educação Integral e Direitos Humanos: Implicações Pedagógicas e Culturais. Coleção Direitos Humanos, João Pessoa: Ed. do CCTA, 2015. p.167.

FREIRE, P. Pedagogia do Oprimido. 10. ed. Rio de Janeiro: Paz e Terra, 1981.

A importância do Ato de Ler: em Três artigos que se completam. 29. ed. São Paulo: Cortez, 1994. p. 87.

Educação como prática de Liberdade. 26. ed. Rio de Janeiro: Paz e Terra, 2002.

GOHN, M. G. M. Educação não formal, participação da sociedade civil e estruturas nas escolas. 2006. Disponível em: <http://www.scielo.br/pdf/ensaio/v14n50/30405.pdf>. Acesso em: 20 ago. 2016. 
GONÇALVES, M.R. Relatório Técnico de Titulação e Delimitação do Território da Comunidade Negra de Paratibe. João Pessoa: INCRA, 2011.

MELO NETO. J. F. Educação Popular: enunciados teóricos. João Pessoa: Editora Imprel, 2015. v. 03.

O'DWYER, E. C. Os quilombos e a prática profissional dos antropólogos. In: O'DWYER, E. C. (Org.). Quilombos: identidade étnica e territorialidade. Rio de Janeiro: FGV, 2002.

ONU, Declaração Universal dos Direitos Humanos. 1948. Disponível em: <http://www. dudh.org.br/declaracao/>. Acesso em: 30 ago. 2016.

SILVA, M. A. B. Lei de Terras de 1850: lições sobre os efeitos e os resultados de não se condenar "uma quinta parte da atual população agrícola". Revista Brasileira de História, v. 35, n. 70, p. 87-107, 2015. Disponível em: <http://www.scielo.br/pdf/rbh/ v35n70/1806-9347-rbh-2015v35n70014.pdf >. Acesso em: 10 out. 2016.

TAVARES, J. L. Apontamentos para a história territorial da Parahyba. Mossoró - PB: Fundação Guimarães Duque, 1982/1989. v. 2.

VALLA, V. A contribuição de Victor Valla ao pensamento da educação popular. Rev. Bras. Educa, Rio de Janeiro, v.14, n. 42, Sept/Dec. 2009.

\section{ENTREVISTAS}

Entrevista com J. P., Coordenador do Projeto Social Paratibe em Ação. Concedida em: 20 jul. 2015, em João Pessoa - PB.

Entrevista com Y.A., uma liderança jovem da Comunidade Quilombola de Paratibe. Concedida em: 27 jul. 2015, em João Pessoa - PB.

Iany Elizabeth da Costa: Possui mestrado em Direitos Humanos, Cidadania e Políticas Públicas pelo programa de Pós-graduação em Direitos Humanos da Universidade Federal da Paraíba (2016), é especialista em Educação Integral e Direitos Humanos pela Universidade Federal da Paraíba (2014). Possui Licenciatura Plena em História pela Universidade Estadual Vale do Acaraú (2010). É Pesquisadora integrante do GESTAR - UFPB, vinculada ao Núcleo de Cidadania e Direitos Humanos NCDH - UFPB. Foi tutora EAD no curso de aperfeiçoamento em Docência em Educação Integral pela Universidade Federal da Paraíba (2015). Tem experiência na área de Educação, com ênfase em Educação Étnico-racial, Educação Integral, Pedagogia, Comunidades Tradicionais e Direitos Humanos.

E-mail: ianyelizabeth@hotmail.com 